Environmental Fate of Organophosphorus Compounds Related to Chemical Weapons

M. L. Davisson, A. H. Love, A. Vance, J. G. Reynolds

February 16, 2005 
This document was prepared as an account of work sponsored by an agency of the United States Government. Neither the United States Government nor the University of California nor any of their employees, makes any warranty, express or implied, or assumes any legal liability or responsibility for the accuracy, completeness, or usefulness of any information, apparatus, product, or process disclosed, or represents that its use would not infringe privately owned rights. Reference herein to any specific commercial product, process, or service by trade name, trademark, manufacturer, or otherwise, does not necessarily constitute or imply its endorsement, recommendation, or favoring by the United States Government or the University of California. The views and opinions of authors expressed herein do not necessarily state or reflect those of the United States Government or the University of California, and shall not be used for advertising or product endorsement purposes.

This work was performed under the auspices of the U.S. Department of Energy by University of California, Lawrence Livermore National Laboratory under Contract W-7405-Eng-48. 


\section{ENVIRONMENTAL FATE OF ORGANOPHOSPHORUS COMPOUNDS RELATED TO CHEMICAL WEAPONS}

M. Lee Davisson, Adam H. Love, Andy Vance, John G. Reynolds

Lawrence Livermore National Laboratory, PO Box 808 L-091, Livermore, CA 94550 


\section{ABSTRACT}

Man-made organophosphorus compounds have been widely distributed throughout our environment as pesticides since their development during and after WWII. Many important studies have documented their relative persistence and toxicity. Development and use of some organophosphorus compounds as nerve agents gave rise to a separate but parallel effort to understand environmental persistence. In this latter case, the experiments have focused mainly on evaporation rates and first-order reaction kinetics. However, because organophosphorus compounds are easily polarized, the ionic content of a surrounding media directly factors into these reaction rates, but limited work in this regard has been done under environmentally relevant conditions. Furthermore, limited experiments investigating persistence of these agents on soil has resulted in widely varying degradation rates. Not surprisingly, no studies have investigated affinities of organophosphorus nerve agents to mineral or organic matter typically found in soil. As a result, we initiated laboratory experiments on dilute concentrations of nerve agent $O$-ethyl S-(2-diisopropylaminoethyl) methylphosphonothiolate (VX) to quantify persistence in simulated environmental aqueous conditions. A quantitative analytical method was developed for VX and its degradation products using High Performance Liquid ChromatographyElectrospray Ionization-Mass Spectrometry (HPLC-ESI-MS). VX hydrolysis rate is known to have a $\mathrm{pH}$-dependency, however, the type of buffer and the relative proportion of different nucleophiles in solution significantly affect the overall rate and mechanism of degradation. For example, dissolved carbonate, a weak nucleophile dominating natural water, yielded pseudo-first order rate constants of $\sim 8 \times 10^{-3} / \mathrm{hr}$ at $\mathrm{pH} 5$ and $2 \times 10^{-2} / \mathrm{hr}$ at $\mathrm{pH} 11$. This small $\mathrm{pH}$-dependent variation departs significantly from widely accepted rates at this $\mathrm{pH}$ range $\left(4 \times 10^{-4} / \mathrm{hr}\right.$ to $\left.8 \times 10^{-2} / \mathrm{hr}\right)$ that were based on chloride and hydroxyl (strong nucleophile) dominated experimental solutions. Because of its overwhelming abundance in $\mathrm{r}$ solution elative to hydroxyl ion, bicarbonate likely effectively competes in nucleophilic attack on phosphorus. The addition of natural dissolved organic matter at $100 \mathrm{mg} / \mathrm{L}$ in $\mathrm{pH} 7$ bicarbonate buffered solution slowed VX hydrolysis rates $\sim 2$ times relative to controls, suggesting hydrophobic interaction. Adsorption experiments derived isotherms from batch aqueous experiments on montmorillonite clay, iron-oxyhydroxide goethite, and on amorphous silica. VX had moderate affinity for montmorillonite and amorphous silica, and very low affinity toward goethite. The addition of dissolved organic matter into solution enhanced VX adsorption to goethite, consistent with its high affinity for hydrophobic organic matter $\left(\log \mathrm{K}_{\mathrm{oc}}=2.52\right)$. Diisopropylaminoethylthiol (DESH), a hydrolysis product of VX showed equivalent adsorption to montmorillonite, and poor affinity to goethite and silica. However, hydrolysis products O-Ethylmethylphosphonic acid (EMPA) and methylphosphonic acid (MPA) strongly adsorbed on goethite, but not on montmorillonite or silica, suggesting a ligand-exchange mechanism. VX degraded rapidly when completely dried onto goethite followed by rehydration, consistent with an irreversible chemical adsorption mechanism.

\section{INTRODUCTION}

Organophosphorus (OP) compounds are widely distributed throughout various synthetic products in the world. They serve many functions in applications such as metal chelation from water, fire retardants and plasticizers for polymers, and high temperature lubricants. Because phosphorus is a group V element and can easily change oxidation states, trivalent OP compounds have found their way into many synthetic chemistry applications. The nucleophilicity of many OP forms lends itself readily to electron transfer reactions. It is no surprise that OP compounds are also key components in terrestrial life. They mainly acts as an energy carrier or transfer point (i.e. ATP), but also forms important cellular lipid structure and function, and, as phosphate, provides the basic bone structure in vertebrates, and serves an important nerve function in animals and insects. In this latter regard, the development and rapid growth in OP chemistry before and after World War II can largely be attributed to the search for effective pesticides in order to avert crop loss. The overwhelming effectiveness of 
many OP pesticides and herbicides developed for commercial use has in part been responsible for more than doubling of crop yields per hectare in developed nations. For example, in the US, approximately 30 million kilograms of OP pesticides were used annually between 1992 and 1997 (Hopkins et al., 2000).

However, the toxicological properties of many current and previous OP pesticide formulations have known mammalian effect. This has given rise to numerous investigations intended to understand pesticide fate (e.g. Wolfe et al., 1977; Meikle and Youngson, 1978; McConnell and Hossner, 1985; Aubin and Smith, 1992; Piccolo et al., 1996; Baldwin et al., 2001). The biological action of OP pesticides targets the central nervous system of insects, arachnids, and invertebrates which have an acetylcholinesterase-based nerve response mechanism. In mammals, this mechanism involves the irreversible binding of OP to receptor sites in acetylcholinesterase and inhibits hydrolysis of acetylcholine. Acetylcholine chemically transmits sodium and potassium ion charge across the synapse that initiates nerve impulse. If acetylcholinesterase is neutralized, then acetylcholine maintains a charge potential on the postsynaptic side of the neural transmitting membrane forcing permanent nerve stimulation. The potency of an OP compound can be qualitatively estimated by its ability and rate to hydrolyze, phosphorylate with an enzyme, or undergo detoxification (Fest and Schmidt, 1983). These changes depend on the physio-chemical properties of the OP formulation. Consequently, formulations developed early on in OP pesticide chemistry had both acute insect and mammalian toxicities mainly due to the fact that they had excellent phosphorylating properties. Later attention given to differences inherent in mammalian physiology exploited formulations that had reduced phosphorylating activity, but that were readily hydrolytically detoxified (Fest and Schmidt, 1983).

The discovery of OP mammalian toxicity by G. Schrader at IG Farben was unfortunately during the early period of Hitler's rise to power, during which time German scientists were required to report all developments of potential military usefulness to government authorities. Schrader furthermore had made his first discovery on what is now known as Tabun and then Sarin gas while searching for formulation for insecticidal use (Fest and Schmidt, 1982). It was the low-dose symptoms on himself and his lab assistant (e.g. vision impairment) that lead to the discovery. Thus was born nerve agent science and its exploitation for military use. The Germans during WWII had developed and manufactured both Sarin and Tabun munitions, but had never used them on the battlefield (Harris and Paxton, 1982). They had further discovered Soman, but never manufactured any in large quantity. The capturing of remains from these development efforts and manufacturing sites were transferred to the US, UK, and Soviet military interests, who pursued determination of their composition, mode of toxicity, and development of protective measures. The UK code named each as GA (Tabun), GB (Sarin), and GD (Soman). The UK and US focused on development of GB munitions, whereas the Russian on GD. Russians also incorporated into their arsenal GA munitions captured from Germany. In the US, GB was manufactured in a five step process, the first two in Alabama, and the latter three at Rocky Mt. Arsenal in Colorado (Smart, 1997). By the mid-1950s the US had produced 15-20K tons of GB (Harris and Paxman, 1982). Military intelligence reported at the time that the Russians, who dismantled, moved, and rebuilt two confiscated Nazi nerve agent plants, were producing large quantities of chemical munitions (GD and GA) and superior protective geared.

In 1952, Ranajit Ghosh, a British chemist, discovered a highly toxic organophosphate compound class that lead to the V-agents. Dermal contact from this class was a 1000 times more toxic than the G-agents, had a low vapor pressure, and a higher viscosity. The compound class was reported to Porton Down in the UK, who subsequently transferred it to the US as part of the Tripartite Agreement at the time (Harris and Paxman, 1982). With further investigation by the US Chemical Corps, VX was selected as the standard munitions grade compound that was subsequently produced in mass (Smart, 1997). The advantage of VX was its persistence in the environment. Whereas the Gagents were volatile and dissipated quickly, VX could be laid down in quantity as a battlefield denial agent that lasted several days to weeks. By 1967 the US had a stockpile of VX up to 5000 tons stored 
in various munitions (Harris and Paxton, 1982). Within the same timeframe, the Soviet Union had developed their own version of V-agent largely based on formulas secretly obtained from the west (Croddy, 2002).

Persistence of OP nerve agents released at large quantities into the environment will largely be controlled by their vapor pressure and hydrolysis rates, which will dictate rates of either their atmospheric dispersion or their hydrolytic inactivation. In the case of G-agents, vapor pressures $(\sim 0.1$ to $1.0 \mathrm{~mm} \mathrm{Hg})$ and hydrolysis rates $\left(\sim 0.03\right.$ to $0.1 \mathrm{hr}^{-1}$ at neutral $\left.\mathrm{pH}\right)$ are relatively high. Their persistence in acute amounts typically lasts on the order of a day. The $\mathrm{V}$-agents have vapor pressures and hydrolysis rates approximately 100 times lower, implying persistence will last weeks to months. Evaporation and hydrolysis have been the determinants for persistence within military policy. Environmental fate of OP compounds is largely measured by persistence as a parent molecule. Although hydrolysis products are measured in some cases where they themselves pose a toxicological hazard, for the most part the rate at which a parent compound disappears is the common measurement approach. However, as observed in many pesticide studies, OP compounds can be retarded in soil by adsorption or transported in water as a parent molecule and still remain bioavailable. Although in the case of large quantity nerve agent dispersal the acute dose will have dissipated by evaporation and hydrolysis, an equivalent knowledge does not exist for their persistence and level of danger from postdispersal residues remaining in the environment.

The requirements for a civilian policy toward accidental or intentional nerve agent contamination requires further inquiry in order to predict potential chronic sub-lethal doses residual in an environment. Limited research has been conducted on OP nerve agent persistence at sub-acute levels and their interaction with surrounding environmental media. In the case of VX, direct observation is limited to examples such as military field experiments conducted approximately 50 years ago that had very little documented controls (e.g. Epstein et al., 1958), or later on from laboratory studies conducted on one soil type under a single simulated condition (e.g. Verweij and Boter, 1976; Kaaijk and Frijlink, 1977). Both of these approaches resulted in relatively rapid disappearance. In contrast, recent works on concrete and a different soil resulted in VX persistence rather than rapid degradation (Wagner et al., 1999; Groenewold et al., 1999). Additional physical property data on OP nerve agents (e.g. $\mathrm{K}_{\mathrm{ow}}, \mathrm{K}_{\mathrm{D}}$, etc.) need to be considered in order to better understand how OP compounds are retarded in environmental matrices and their subsequent bioavailability. This will largely be governed by the polarizability of the phosphoryl group as well as the hydrophobicity of the leaving or ester groups. Little hypothesis-oriented research has been accomplished for nerve agents in this regard.

This report attempts to outline fundamental differences between OP pesticide and nerve agent chemistries with respect to the environment. It furthermore, illustrates a transport and fate framework more relevant to counter-terrorism or post event clean-up. Lastly, this report documents our own research on VX nerve agent and its interaction with common environmental matrices. We show that VX hydrolysis rates are significantly affected by other dissolved species in water, that it has a relatively high affinity to clay minerals and natural organic matter, and can be catalytically degraded by other minerals.

\section{DEVELOPMENT AND GENERAL CHARACTERISTICS OF ORGANOPHOSPHORUS ACIDS AND THEIR DERIVATIVES}

The following text summarizes detailed discussion presented in Fest and Schmidt (1982) and (1983) unless otherwise indicated. Early in the $19^{\text {th }}$ century, important steps in phosphate ester chemistry were taken by reacting phosphoric acid with alcohol and pyrophosphoric acids with alkylhalides to form basic organophosphorus compounds. As early as 1872, phosphinic acids were first 
synthesized by A.W. Hoffman, which set the stage for development of phosphonate synthesis. This was first achieved by C.A.A. Michaelis and Th. Becker in Germany by reacting sodium dialkyl phosphite with ethyl iodide to produce di-O-ethyl ethyl phosphonate. In 1903 they went on to synthesize phosphorus-nitrogen compounds, including phosphoramidates and phosphoramidocyanidates. However, they never recognized the high toxicity of this latter formulation. In 1905 A.E. Arbusov in Russia, followed up on Michealis' early work, reacted triethylphosphite with ethyl iodide to form di-O-ethylethylphosphonate, which came to be known as the Arbusov reaction.

In 1932, W. Lange and G. v. Krueger were the first to prepare esters of monofluorophosphoric acid from silver salts and alkyl iodide. They were also the first to report the common toxicological properties of acetocholinesterase inhibition. In the late 1930s, G. Schrader in Germany was attempting to develop acid fluorides that had acaricidal and aphicidal activity for crop protection. In one process he converted $N, N$-dimethyl phophoramidochloridate to the difluoridate form using potassium fluoride, but found this to be only weakly toxic. He followed by reacting with potassium cyanide instead and subsequently produced the dicyanate form Tabun. Replacing the dialkylamino group with a dialkyl group, Schrader was later led to the synthesis of Sarin. In 1941, B.C. Saunders in Britain prepared esters and ester amides of phosphorofluoridates specifically for high toxicity insecticides, for which they documented its high inhalation toxicity, but they remained a secret within the Ministry of Supply for the duration of the war. Because Schrader was required to report his discoveries to the Nazi authorities, subsequent synthetic development at the Heereswaffenamt in Heidelberg in 1944 led to the development of Soman.

Emergence from WWII with developed chemistry for highly toxic organophosphorus compounds gave rise to early insecticides, such as Dimefox (tetramethylphosphorodiamidic fluoride) and Schradan (octamethylpyrophosphoric tetra-amide). Owing to their high mammalian toxicity, these early compounds were subsequently superseded by more innocuous versions such as those of the Systox group (e.g. demeton Diethyl O-(and S-)(2-(ethylthio)ethyl) phosphorothioate). It is interesting to note the gross similarities between this latter group and what have become the $\mathrm{V}$-agents. As a matter of fact Ghosh in 1952 at the time was employed by the Plant Protection Laboratories of the Imperial Chemical Industries and was developing insecticidal formulas, which led to the discovery of the highly toxic V-class. In general however, organophosphorus insecticide chemistry has move away from organophosphonates toward the organophosphates mainly because of their lower mammalian toxicities and their lower environmental persistence. In almost all cases of organophosphorus insecticides in use today, the formulations are derivatives of phosphoric acid, the majority of which are thiophosphoryl groups (Quin, 2000). For example, it was recognized early on that strong electron withdrawing groups attached to the phosphate formed leaving groups during hydrolysis, and promoted shorter environmental residence times. One such example is Parathion, whose $O$-methyl version is still in use today, was originally synthesized by Schrader in 1944. Even safer versions are available and used today including Malathion (S-1,2-bis(ethoxycarbonyl)ethyl O,O-dimethyl phosphorodithioate) and Phosmet ( $\mathrm{N}$-(dimethoxyphosphinothioylthiomethyl)phthalimide). Organophosphonates have arrived later on the agricultural market as broad spectrum herbicides, such as glyphosate $(\mathrm{N}$ (phosphonomethyl)glycine), which have low mammalian toxicities and functions as an inhibitor of aromatic compounds synthesis in plants.

A summary of pentavalent organophosphorus compounds relevant to this report can be made by illustrating 6 general coordinated phosphorus centers:

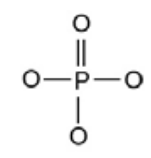

Phosphates
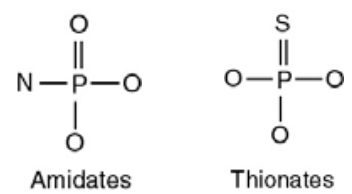

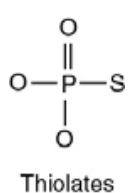

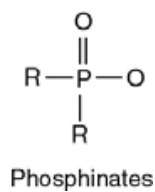


Phosphates can have many ester combinations, but most commonly they are tri-alky, di-alkyl, and mono-akyl acids or one ester of enol, phenol, benzyl, pyro, or a cyclic group. In the trialkyl case, both alkaline and acidic conditions hydrolyze via nucleophilic attack on the phosphorus, whereas in neutral solutions preferential attack on the $\alpha$-carbon occurs instead. Only in the case where competing nucleophiles of a "hard base" type (other than $\mathrm{OH}$ ) does attack occur on the phosphorus "hard acid" (see Pearson, 1963 for further use of terminology). Benzyl esters undergo the same hydrolysis mechanism on the $\alpha$-carbon. All other forms mostly undergo nucleophilic attack on the phosphorus. Additional mechanisms of note include the amidates, where under basic conditions the nitrogen is free to participate in $\pi$-bonding with phosphorus, thus making the center more stable (less positively charged). However, in acidic solutions the nitrogen is protonated and hydrolysis via amino-P cleavage readily occurs (e.g. Larsson, 1953). A phosphorus-carbon bond of phosphonates enhances hydrolysis at high $\mathrm{pH}$ because the alkyl group is non-polar and carbon does not participate in $\pi$-bonding with phosphorus, placing greater polarity between the P-O bonds. On the other hand, phosphonates and phosphinates are comparatively more stable in acidic conditions than the phosphates.

The phosphorylating property of organophosphorus compounds have by far the most important role in determining toxicity. Following the arguments of Schrader's "acyl" rule, a generalized form can be used to better illustrate this property:<smiles>[R7]P([R])(=O)[GeH3]</smiles>

The following rules apply for phosphorylating properties: 1) oxygen or sulfur must be directly bonded to the phosphorus; 2) $\mathrm{R}^{1}$ and $\mathrm{R}^{2}$ must be alkoxy, alkyl, or amine; 3) "the acyl" comprises a leaving group typically of $\mathrm{H}, \mathrm{C}, \mathrm{N}, \mathrm{O}, \mathrm{S}$, or a halogen with the general configuration of P-XYZ (Clark et al., 1964). Phosphorylation is enhanced when the $P-X$ bond is weak and $Z$ is as electronegative as possible. The "acyl" rule with this important leaving group corollary combined with general hydrolysis mechanism opened the door to the development of many insecticide formulations currently available and on the market. Note, that manipulation of the leaving group configuration will ultimately dictate the hydrolysis rate and mechanism, but have less influence on the phosphorylating potential, since the latter depends on reaction with acetylcholinesterase under physiological conditions, and the former on the rate at which the compound can be hydrolytically deactivated by the biological host.

\section{TRANSPORT AND FATE FRAMEWORK}

Chemical transport and fate is largely governed by the fundamental physical properties of a particular compound. Its transition among the different physical states (i.e. gas, liquid, or solid) will depend on surrounding environmental conditions. Generally the physical properties of vapor pressure, water solubility, and octanol-water partitioning coefficient $\left(\mathrm{K}_{\mathrm{OW}}\right)$ are utilized to estimate chemical behavior in the environment. All three properties are temperature dependent and for compounds with relatively low boiling points, the vapor state becomes the dominant factor in chemical transport. For low boiling point compounds that have high solubility, water transport mechanisms dominate, and consequently, low boiling point but high $\mathrm{K}_{\mathrm{OW}}$ compounds will adsorbed to hydrophobic surfaces and have retarded transport. This latter character has stimulated much research into prediction of industrial contaminant fate and its bioaccumulative effect (e.g. MacKay et al., 1985; MacKay and Paterson, 1991; Maddalena et al. 1995). The simplicity of this transport and fate framework is limited for predicting actual 
concentrations and partitioning behavior (MacKay and Paterson, 1981), particularly when reactivity is taken into account. For the most part the chemical complexity of the environment introduces many small variables whose net affect on chemical transport and fate are difficult to predict. For example, presence of aerosols can play an important role on the overall transport of a compound with a high vapor pressure and high solubility (e.g. Cousins and MacKay, 2001). Mineral adsorption on surfaces can occur both through hydrophobic and ionic mechanisms, and the degradability of a compound can be controlled by both abiotic reactions with dissolved species in water, or by metabolic uptake by microorganisms (e.g. Cahill and MacKay, 2003). The complexity of the environment is further accentuated within an urban setting (Fig. 1), and categories of surface chemistry and their net effect on chemical fate are varied. The role of each potential reactive pathway is rarely investigated for any one compound, and limited for even classes of compounds.

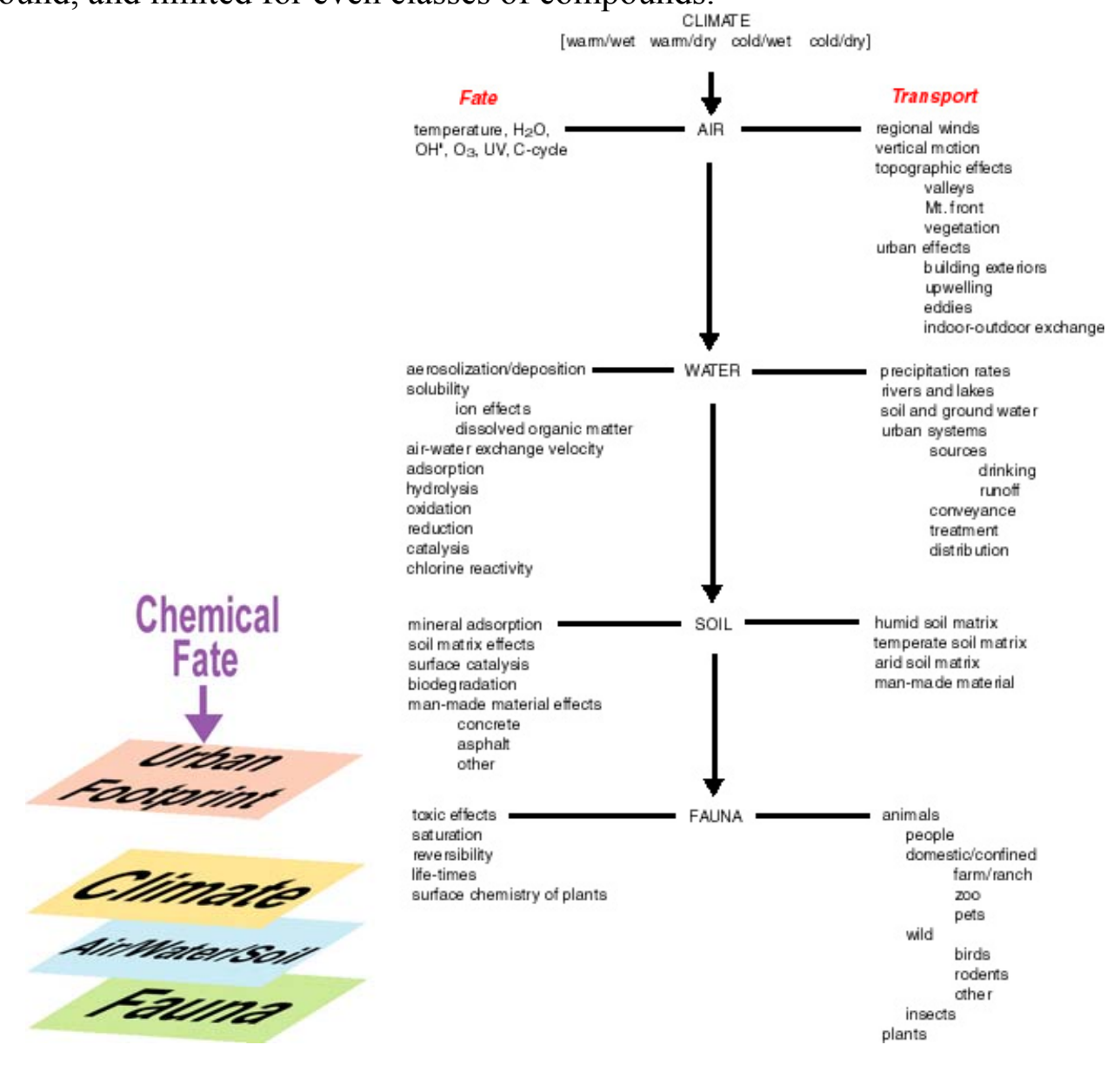

Figure 1. The chemical complexity of the outdoor environment particularly for urban areas is not captured or represented within current advection-dispersion hazard prediction modeling codes. Furthermore, quantitative data measuring the chemical interaction of nerve agents with these environmental materials is lacking.

Nevertheless, there is still a driving need to better predict chemical transport and fate, particularly within both the military and urban emergency response areas where protection policy of troops or large populations needs continual improvement. Currently high fidelity advection-dispersion transport models used at urban scales currently have limited chemical predictive capability, but rather emphasize population exposure and dose prediction through inhalation (e.g. Warner et al., 2001; Chang et al., 2003; Warner et al. 2004). Chemistry solvers imbedded in these types of models will be computationally demanding and furthermore be largely limited by the lack of experimental data. The 
simplest approach would be the case of atmospheric plume advection-dispersion and first-order rate decay, which is the basis of current modeling development approaches. However, this does not address reactive transport associated with surface interaction, adsorption to particulate matter, and low-dose residuals lingering in the environment. These latter elements suffer from the lack of quantitative experimental data in which to base predictive modeling.

Post-vapor persistence of agents is never addressed in these modeling formats. This entails the adsorption, condensation, or retardation of dispersed agents onto or within materials in complex terrains. Extensive laboratory work documenting chemical agent evaporation from a variety of materials encountered during military operations (e.g. King, 2000) has led to policy development of troop protection and decontamination protocols. However, attempts at simulating this persistence, even from a simple evaporative flux approach, has been limited, even though toxicity of the environment remains high.

\section{PHYSICAL CHEMISTRY AND ENVIRONMENTAL BEHAVIOR OF NERVE AGENTS}

\section{$\underline{\text { Physical Properties }}$}

This section outlines general properties and environmental behavior of familiar nerve agents accumulated from various literature sources. It is not intended to be a thorough review of these agents, but rather an illustration of difference in their properties and their relationship to environmental transport and fate. Special emphasis will be placed on VX since later sections detail experiments conducted on this agent at LLNL.

Below are the molecular structures of common nerve agents that are in the same convention as used earlier. With this format Schrader's "acyl" rule can be illustrated. For example, all structures are phosphonates, except GA which is a phosphoroamidate, and all have a phosphonyl linkage to oxygen. For the agents GB, GD, and GF the leaving group is fluoride, whereas in GA it is the cyano group at neutral and alkaline $\mathrm{pH}$ ), and for VX the aminothiol. The electronegativity of fluoride and the nonpolar methyl group decreases the electron density around phosphorus.

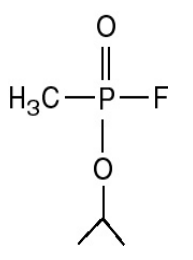

$G B$

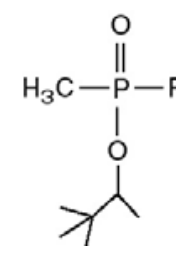

$G D$

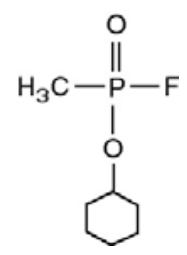

$G F$

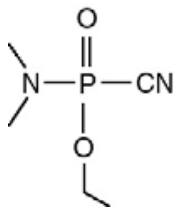

GA

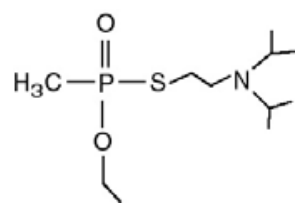

$V X$

This provides an efficient phosphorylating property by base catalysis through the serine moiety of the acetylcholinesterase. Similarly, GA and VX also undergo phosphorylation, but its mode of exposure and dose are slightly different than the other agents (Table 1). Whereas the high vapor pressures of GB, GD, and GF make them high inhalation toxicants (Table 2), they are less efficient at being adsorbed through the skin compared to VX. Furthermore, the lipophilic character of the amino function on VX provides a mechanism to be additionally soluble in fat. Note that the toxicity through inhalation varies much less among all the agents than percutaneous exposure. GA is inherently less stable in aqueous solution, hydrolyzing approximately 20 times faster at near-neutral $\mathrm{pH}$ than the other $\mathrm{G}$ agents (Clark, 1989). However, GA is relatively more stable in alkaline conditions (hydrolyzes $\sim 2$ times slower than other $\mathrm{G}$ agents) because of the propensity of the deprotonated amino nitrogen $\pi$ bonding with phosphorus. VX hydrolyzes slower because sulfur is less electronegative, which increases 
electron density higher around $\mathrm{P}$ and reduces the rate of hydroxyl attack. Furthermore, the remaining elements on the leaving group are poor electron withdrawers.

Table 1. Estimated Toxicity of Common Nerve Agents (after Wiener and Hoffman, 2004).

\begin{tabular}{lcccr} 
& LD50(percutaneous) & LC50 & LCt50 & IDLH \\
\hline GA (Tabun) & $1 \mathrm{gm} /$ person & $2 \mathrm{ppm}$ & $100-400 \mathrm{mg} \times \mathrm{min} / \mathrm{m} 3$ & $0.03 \mathrm{ppm}$ \\
GB (Sarin) & $1.7 \mathrm{gm} /$ person & $1.2 \mathrm{ppm}$ & $50-100 \mathrm{mg} \times \mathrm{min} / \mathrm{m} 3$ & $0.03 \mathrm{ppm}$ \\
GD (Soman) & $0.35 \mathrm{gm} /$ person & $0.9 \mathrm{ppm}$ & $25-70 \mathrm{mg} \times \mathrm{min} / \mathrm{m} 3$ & $0.008 \mathrm{ppm}$ \\
GF & $0.03 \mathrm{gm} /$ person & unknown & unknown & unknown \\
VX & $0.01 \mathrm{gm} /$ person & $0.3 \mathrm{ppm}$ & $5-50 \mathrm{mg} \times \mathrm{min} / \mathrm{m} 3$ & $0.002 \mathrm{ppm}$ \\
\hline
\end{tabular}

LD50: Nerve agents are among the most lethal agents available that have been developed for military use.

LD50 (percutaneous): Dose required to kill $50 \%$ of those exposed, is in the milligram range for many agents.

LCt50 - inhalational route: The concentration-time product is a measure of exposure to a vapor or aerosol over time.

IDLH: Concentration of toxin in air that is "immediately dangerous to life and health."

Table 2. Physical Properties

\begin{tabular}{|l|l|l|l|l|l|l|l|}
\hline & $\mathrm{MW}$ & density & $\mathrm{BP}{ }^{\circ} \mathrm{C}$ & $\mathrm{Vp} \mathrm{mm} \mathrm{Hg} 20^{\circ} \mathrm{C}$ & Sol. g/L 20 ${ }^{\circ} \mathrm{C}$ & $\log \mathrm{K}_{\mathrm{ow}}$ & $* \log \mathrm{K}_{\mathrm{H}}$ \\
\hline GB & 140.1 & 1.102 & 147 & 1.48 & miscible & 0.24 & - \\
\hline GD & 182.2 & 1.022 & 190 & 0.92 & 21 & $\sim 20$ & -7.78 \\
\hline GF & 180.2 & 1.120 & 239 & 0.044 & 72 & -4.98 & -6.28 \\
\hline GA & 162.1 & 1.077 & 246 & 0.037 & 30 & -1.4 & -6.96 \\
\hline VX & 267.37 & 1.012 & 298 & 0.0007 & 2.06 & -8.09 \\
\hline
\end{tabular}

* Calculated by the ratio of $\mathrm{Vp} / \mathrm{Sol}$. Units in atm $/ \mathrm{m}^{3}-\mathrm{mol}$.

Because of their polar character all the common nerve agents have relatively high solubilities (Table 2). The $\mathrm{G}$ agents also have high vapor pressures that indicate even in the presence of water, they will have a high volatility. Equilibrium water-vapor partitioning constants $\left(\mathrm{K}_{\mathrm{H}}\right)$ were calculated for each agent in Table 2 . The partitioning coefficient and the vapor pressure are systematically

proportional, indicating the lower the vapor pressure the more agent remains solubilized. Note also that the octanol-water partitioning coefficient $\left(\mathrm{K}_{\mathrm{OW}}\right)$ indicates that the more lipophilic character of the ester of GD (and likely GF), as well as the leaving group of VX imparts a significant hydrophobicity relative to GA and GB. As a result, the partitioning into a hydrophobic phase will be further expressed for GD, $\mathrm{GF}$, and VX in a three-phased system of air, water, and hydrophobic material.

\section{Background on VX}

To understand the fundamental mechanisms of nerve agent fate in various complex media, experiments need to be conducted under laboratory or field conditions that specifically serve threat, response, and counter-terrorism objectives (i.e. part per million to part per billion concentrations). Environmental conditions that may 1) reduce or accelerate degradation (e.g. Epstein, 1970; Wagner et al., 2001a), 2) promote mobility of compounds (e.g. Piccolo and Celano, 1994; Korenyi-Both et al., 2000), and 3) facilitate irreversible binding (McBride and Kung, 1989) are critical to secondary exposure analysis from nerve agents or successful detection of their manufacturing signatures. Predicting the fate of a nerve agent, or its signature compounds, in an environmental setting requires either understanding its behavior empirically from a large body of examples, or fundamentally based on knowledge of its reaction chemistry. Currently, neither source of predictive knowledge is adequate for VX. Empirical knowledge is limited to examples such as military field experiments conducted approximately 50 years ago that had very little documented controls (Epstein et al., 1958; Kingery and Allen, 1995), or later on from laboratory studies conducted on one soil type under a single simulated condition (Verweij and Boter, 1976; Kaaijk and Frijlink, 1977). Both of these approaches resulted in relatively rapid disappearance of VX. In contrast, recent works on concrete and a different soil resulted in VX persistence rather than rapid degradation (Wagner et al., 1999; Groenewold et al., 1999). 
Using the hydrolysis pathways outlined by Epstein et al. (1974), the observed hydrolysis rate constant for VX varies orders of magnitude and involves 5 degradation pathways (Fig. 2). Using the hydrolysis rates for each pathway, a model of the concentration of VX and some of its degradation products can be projected for different $\mathrm{pH}$ values. The hydrolysis of $\mathrm{VX}$ at $\mathrm{pH} 5$ and $\mathrm{pH} 8$ demonstrate that the behavior of VX can have significant variation over a range of reasonable environmental conditions. At $\mathrm{pH} 5$, the half-life of $\mathrm{VX}$ is $\sim 100$ days, whereas at $\mathrm{pH} 8$ the half-life is $\sim 9$ days. At $\mathrm{pH} 5$ EMPA and MPA, which have low toxicity, are the most abundant degradation product, whereas at $\mathrm{pH}$ 8 the most abundant degradation product is S-(2-diisopropylaminoethyl) methylphosphonic acid (EA2192), which has a toxicity similar to VX. Thus, even for simple aqueous systems the environmental conditions play an important role in the fate of VX and its degradation products.

1)

2a)

2b)

2c)

3)
VX- $\mathrm{H}^{+}+\mathrm{H}_{2} \mathrm{O} \rightarrow$ EMPA + mercpatan $+\mathrm{H}^{+}$

VX- $\mathrm{H}^{+}+\mathrm{OH}^{-} \rightarrow$ EMPA + mercpatan $+\mathrm{H}^{+}$

$\mathbf{V X}+\mathrm{H}_{2} \mathrm{O} \rightarrow \mathbf{E A 2 1 9 2}+\mathrm{EtOH}+\mathrm{H}^{+}$

VX $\rightarrow$ EMP-S $^{-}+$ethyleneimmonium

$\mathbf{V X}+\mathrm{OH}^{-} \rightarrow \mathbf{E M P A}+$ mercpatan $+\mathrm{H}^{+}$

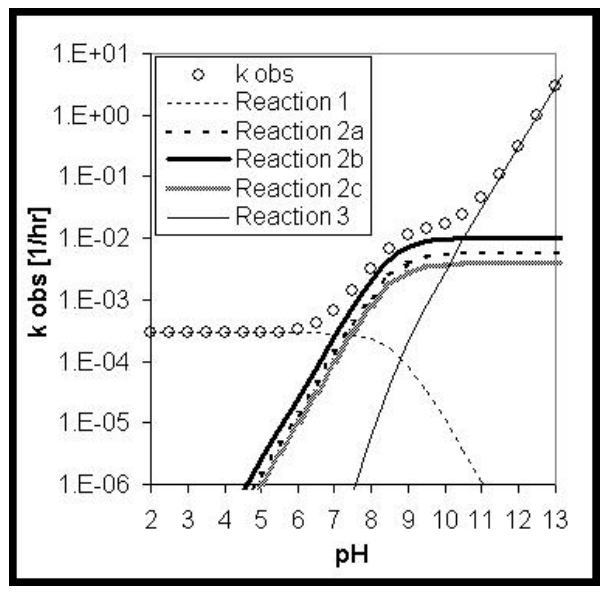

Figure 2. VX exhibits five separate hydrolysis pathways whose rate and product concentrations depend on $\mathrm{pH}$.

Environmental behavior of VX is complicated because its structure has functional groups that can be potentially basic or acidic while exhibiting hydrophobic properties. In addition, VX lacks a strong electron-withdrawing leaving group common to most organophosphorus pesticides that would increase its potential for degradation. Chemical surrogates of organophosphorus nerve agents (compounds with similar structures but with low toxicity - Table 3), do not share the same physiochemical properties. This suggests VX may behave significantly differently in environmental matrices than compounds used as surrogates, and therefore increase in uncertainty in persistence forecasts, depending on prevailing $\mathrm{pH}$, temperature, and affinity toward adsorptive or reactive surfaces. Little is known about the fate of VX at trace-levels and whether adsorption on soil surfaces or complexation with natural organic matter may affect its degradation rate. Little hypothesis-oriented research has been accomplished to determine under what environmental conditions VX is more likely to persist in an adsorbed or complexed form. Adsorbed or complexed VX may potentially be more resistant to natural degradation or decontamination and thus still have the potential for secondary release and exposure. Mechanistic knowledge of its environmental fate would also promote improved signature detection of illicit activities for Chemical Weapons Convention monitoring. Such understanding of where and how $\mathrm{VX}$ and its signatures persist could allow environmental samples to be targeted based on physiochemical affinities. 
Table 3. VX and Common Surrogates

\begin{tabular}{|c|c|c|}
\hline Name & Structure & Log Kow \\
\hline VX & & 2.1 \\
\hline Malathion & & 2.4 \\
\hline Glyphosate & & -4.0 \\
\hline $\begin{array}{c}\text { Diisopropyl } \\
\text { methylphosphonate }\end{array}$ & & 1.0 \\
\hline $\begin{array}{c}\text { Dimethyl } \\
\text { methylphosphonate }\end{array}$ & & -0.6 \\
\hline
\end{tabular}

\section{EXPERIMENTAL}

\section{$\underline{\text { LLNL's Forensic Science Center }}$}

VX is a highly toxic compound that can harm exposed individuals at extremely small doses (e.g. dermal $\mathrm{LD}_{50}<0.1 \mathrm{mg} / \mathrm{kg}(\mathrm{NRC}, 1997)$ ) and should be handled only in appropriate facilities. In addition, international treaties tightly regulate possession of VX and handling is only permitted in laboratories approved for chemical warfare agents under strict security. The Forensic Science Center at Lawrence Livermore National Laboratory (LLNL) has the authority and capability to synthesize and handle small, dilute quantities of VX through its accreditation as a United States Designated Laboratory for the Organization for the Prohibition of Chemical Weapons, which performs monitoring for verification of international treaties that ban chemical weapons. Thus, this resource enables tracelevel environmental research of CW compounds to occur at LLNL.

\section{Reagents}

Dilute solutions of VX (800 ppm of VX in $10 \mathrm{~mL}$ of methylene chloride) were synthesized at LLNL and the purified product was quantified using GC-AED. The purity of VX was $>99 \%$. The chemicals were purchased as follows: methyl phosphonic acid (MPA), O-ethyl methylphosphonic acid (EMPA), HPLC grade methanol, water, formic acid, ammonium formate, sodium citrate, 3-(NMorpholino)propanesulfonic acid (MOPS) - Sigma Chemical Co., St. Louis, MO; powdered activated charcoal - MCB Manufacturing Chemists, Inc., Cincinnati, OH; montmorillonite - Aldrich Chemical Co., Milwaukee, WI; sand, ferric chloride - J.T. Baker, Phillipsburg, NJ; Suwanne River fulvic acid International Humic Substances Society, St. Paul, MN; anhydrous sodium carbonate - Mallinckrodt Chemical Works, St. Louis, MO. Goethite was synthesized from ferric chloride according to Schwertmann and Cornell (1991). 
$\underline{\text { LC-MS Conditions and Analysis }}$

A ThermoFinnigan Surveyor with quaternary pump and autosampler was fitted with a $150 \mathrm{x}$ $4.6 \mathrm{~mm}$ ID Supelco C18 bonded silica column with 5 um particle size, matching guard column, and stainless steel frits prefilter. Conditions were modeled after those of Read and Black (1999) and Black and Read (1998). However isocratic conditions provided superior quantitative reproducibility to the gradient elutions. Separate chromatographic runs were used for VX and the phosphonic acid degradation products. The 5-min isocratic elution for VX was $60 \%$ water/ $40 \%$ methanol with $1 \%$ formic acid at $0.2 \mathrm{ml} / \mathrm{min}$; for MPA and EMPA, 95\% water/ 5\% methanol with $0.02 \%$ ammonium formate. Aqueous injections of $10 \mathrm{ul}$ were made from $200 \mathrm{uL}$ silanized inserts within $2 \mathrm{ml}$ HPLC vials using the autosampler.

The column effluent was directed into the ThermoFinnigan LCQ Advantage MS via an electrospray interface resulting in lower quantification limits than atmospheric pressure chemical ionization source. The positive ion source conditions were as follows: spray voltage $5.5 \mathrm{kV}$, capillary temperature $325^{\circ} \mathrm{C}$, capillary voltage $16 \mathrm{~V}$, sheath gas nitrogen set at a flow meter of 23 , auxiliary gas set at a flow meter of 45 . VX was quantified in positive mode $[\mathrm{M}+\mathrm{H}]^{+}$at $\mathrm{m} / \mathrm{z} 268$. MPA and EMPA were quantified in negative mode $[\mathrm{M}-\mathrm{H}]^{-}$at $\mathrm{m} / \mathrm{z} 95$ and 123 , respectively. VX had a linear response in the range of 0.005 to $5 \mathrm{ppm}$, with a quantification limit of $0.005 \mathrm{ppm}$ based on an ion current peak area with a signal to noise of 2 or greater. MPA and EMPA had a linear response from 1 to 100 ppm, with quantification limits of $1 \mathrm{ppm}$ based on an ion current peak area with a signal to noise of 2 or greater. The difference in sensitivity between VX and the phosphonic acids is presumably because of lower positive ionization efficiency of the hydroxyl sites of the acids compared with the amino site on VX. Precision using this methodology was typically 5-10\%.

Compounds Tracked During Fate Experiments

Formal Name

$\begin{array}{lc}\text { Formula } & \text { Common Name } \\ \mathrm{C}_{11} \mathrm{H}_{26} \mathrm{NO}_{2} \mathrm{PS} & \mathrm{VX}\end{array}$

1.O-Ethyl-S-[2-(diisopropylamino)ethyl] methylphosphonothioate (nerve agent)

2. O-Ethyl-S-[2-(diisopropylamino)ethyl] methylphosphonothioc acid $\mathrm{C}_{8} \mathrm{H}_{22} \mathrm{NO}_{2} \mathrm{PS}$ (precursor and degradation product)

3. O-Ethylmethylphosphonic acid (degradation product)

4. Diisopropylaminoethylthiol (precursor and degradation product)

5. Diethylmethylphosphonate (precursor)

$\mathrm{C}_{3} \mathrm{H}_{9} \mathrm{O}_{3} \mathrm{P} \quad$ EMPA

$\mathrm{C}_{8} \mathrm{H}_{19} \mathrm{NS} \quad$ DESH

$\mathrm{C}_{5} \mathrm{H}_{11} \mathrm{PO}_{3} \quad$ DEMP

\section{Hydrolysis Experiments}

VX hydrolysis experiments (Table 4) were run for 28 days in disposable Teflon ports of an Argonaut Technologies Quest 210 parallel synthesizer. The parallel synthesizer allowed the solution to be mixed continuously with a Teflon stir bar while remaining sealed. Thirteen ports were filled with 10 $\mathrm{mL}$ of solution with various buffer conditions. One port had deionized water equilibrated with atmospheric $\mathrm{CO}_{2}$. Three ports had deionized water buffered with $1 \mathrm{mM}$ citrate at $\mathrm{pH}$. Three ports had deionized water buffered with $1 \mathrm{mM}$ MOPS at $\mathrm{pH}$ 7. Three ports had deionized water buffered with 1 $\mathrm{mM}$ carbonate, initially at $\mathrm{pH} 11$. Three ports had deionized water buffered with $10 \mathrm{mM}$ carbonate at $\mathrm{pH}$ 11. For each set of the buffer conditions, one of the ports had $100 \mathrm{mg} / \mathrm{L}$ of dissolved organic matter from Suwanne River fulvic acid and another had $1000 \mathrm{mg} / \mathrm{L}$ goethite. After the solutions were allowed to equilibrate overnight, $12.5 \mathrm{uL}$ of the $\mathrm{VX}$ in methylene chloride stock solution was added to each solution, for a final VX concentration of $1 \mathrm{ppm}$. Each solution was analyzed periodically by sampling $\sim 500 \mathrm{uL}$ through a valve at the bottom of each port and filtering using a syringe filter. 
Table 4. VX Hydrolysis Experiments

\begin{tabular}{|l|l|l|l|l|l|}
\hline & DI Water & $\begin{array}{l}1 \mathrm{mM} \text { Citrate } \\
(\mathrm{pKa}=4.8)\end{array}$ & $\begin{array}{l}1 \mathrm{mM} \text { MOPS } \\
(\mathrm{pKa}=7.2)\end{array}$ & $\begin{array}{l}1 \mathrm{mM} \text { Carbonate } \\
(\mathrm{pKa}=6.3,10.3)\end{array}$ & $\begin{array}{l}10 \mathrm{mM} \\
\text { Carbonate } \\
(\mathrm{pKa}=6.3,10.3)\end{array}$ \\
\hline Water only & $\mathrm{X}$ & $\mathrm{X}$ & $\mathrm{X}$ & $\mathrm{X}$ & $\mathrm{X}$ \\
\hline Goethite & & $\mathrm{X}$ & $\mathrm{X}$ & $\mathrm{X}$ & $\mathrm{X}$ \\
\hline DOM & & $\mathrm{X}$ & $\mathrm{X}$ & $\mathrm{X}$ & $\mathrm{X}$ \\
\hline
\end{tabular}

\section{Adsorption Experiments}

VX adsorption experiments were performed in silanized $25 \mathrm{~mL}$ glass scintillation vials. Each vial was filled with $10 \mathrm{~mL}$ of deionized water and $12.5 \mathrm{uL}$ of the VX in methylene chloride stock solution was added to each solution, for a final VX concentration of $1 \mathrm{ppm}$. This amount of methylene chloride was fully soluble in the aqueous solutions. Powdered activated charcoal, montmorillonite, and goethite were used to construct adsorption isotherms by adding a measured amount of solid into each vial, shaking vigorously for 1 minute and allowing the solution to equilibrate for 5 to $10 \mathrm{~min}$, which had been previously demonstrated to be adequate (data not shown). For adsorption isotherms of montmorillonite and goethite individually mixed with Suwanne River fulvic acid, $100 \mathrm{mg} / \mathrm{L}$ solutions of fulvic acid were allowed to equilibrate overnight with the solid substrate. The next day these vials were spiked with VX from $1 \mathrm{ppm}$ to $0.1 \mathrm{ppm}$, shaken, and allowed to equilibrate. After equilibration, the vial was shaken vigorously again and $500 \mathrm{uL}$ was sampled using a syringe, filtered at $0.45 \mathrm{um}$, and analyzed using LC-MS within a few hours of sampling.

\section{Enhanced Degradation on Goethite Experiments}

The experiment investigating the degradation of VX on goethite were performed in $25 \mathrm{~mL}$ silanized scintillation vials. Each of three vials had $50 \mathrm{mg}$ of goethite added. Two vials had $100 \mathrm{uL}$ of deionized water added, enough to wet the mineral surface but without any free water. Controls 1) with no solid and 2) with $50 \mathrm{mg}$ of dry sand were used for comparison. $1 \mathrm{~mL}$ of $50 \mathrm{ppm} \mathrm{VX}$ in methylene chloride was added to each vial, which was shaken vigorously and the cap removed. The methylene chloride was allowed to evaporate overnight in a fume hood. The next day $2.5 \mathrm{~mL}$ of water was used to elute the VX from the goethite surfaces of the dry goethite and one wet goethite. The last vial of wet goethite with VX was allowed to completely dry. A sample was taken with a syringe, filtered at 0.45 um, and analyzed using LC-MS.

\section{RESULTS AND DISCUSSION}

\section{$\underline{\text { Hydrolysis }}$}

The VX hydrolysis results are shown in Figure $2 \mathrm{a}-2 \mathrm{~d}$ as ratios of the measured VX concentration relative to its initial value. The $1 \mathrm{mM}$ citrate buffered solutions at pH 5 (Fig. 2a) resulted in the slowest hydrolysis, yielding a uniform rate for the different matrices. Note, however, that deionized water, which had a $\mathrm{pH}$ of $\sim 5$, hydrolyzed VX significantly faster $\left(\sim 0.2\right.$ day $\left.^{-1}\right)$ than the buffered solutions $\left(0.01-0.03\right.$ day $\left.^{-1}\right)$. At $\mathrm{pH} 7$, buffered with $1 \mathrm{mM}$ MOPS, the deionized water and the water with goethite had similar hydrolysis rates of $\sim 0.2$ day $^{-1}$, whereas the water with Suwannee River fulvic acid had a significantly slower hydrolysis rate, 0.09 day $^{-1}$ (Figure $2 \mathrm{~b}$ ). The waters buffered using $10 \mathrm{mM}$ carbonate at $\mathrm{pH} 11$ all had similar hydrolysis rates of $\sim 0.3-0.5$ day $^{-1}$ (Figure 2c). Water buffered using only $1 \mathrm{mM}$ carbonate was initially at $\mathrm{pH} 11$, but over the course of the hydrolysis experiment the $\mathrm{pH}$ dropped from 11 to 9 and then to 7 (Figure 2d). Nonetheless, the hydrolysis of VX remained constant, with the rate of the water and water with goethite having a hydrolysis rate of 0.21 days $^{-1}$ and the water with fulvic acid had a hydrolysis rate that was somewhat slower at 0.18 day $^{-1}$. 

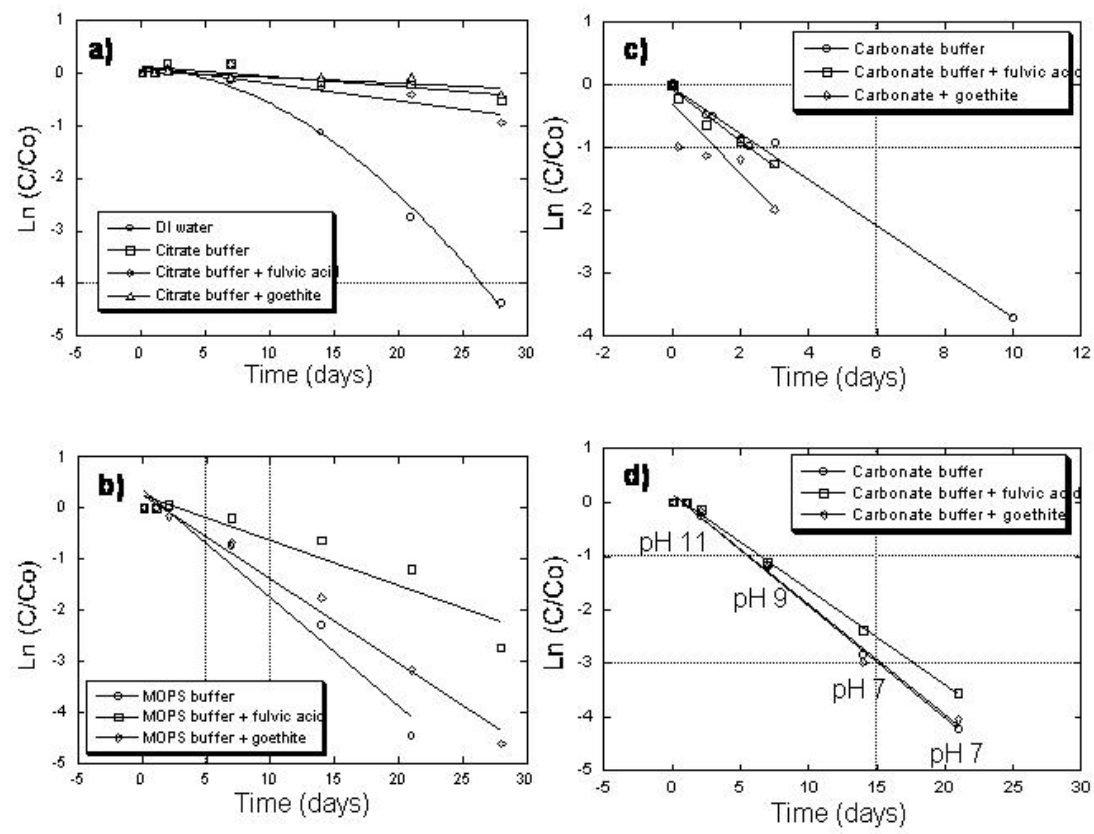

Figure 2a-2d. Hydrolysis of VX in water plotted to linearize first order rate constants a) $\mathrm{pH} 5$ deionized water and $\mathrm{pH} 5$ water buffered with $1 \mathrm{mM}$ citrate b) $\mathrm{pH} 7$ water buffered with $1 \mathrm{mM}$ MOPS buffer c) $\mathrm{pH} 11$ water buffered with $10 \mathrm{mM}$ sodium carbonate d) water buffered with 1 $\mathrm{mM}$ carbonate initially at $\mathrm{pH} 11$ that subsequently decreased to $\mathrm{pH}$ 7. $\mathrm{Ln}$ is the symbol for the $\log _{\mathrm{e}} ;(\mathrm{C} / \mathrm{Co})$ is the aqueous concentration normalized by the initial concentration.

Epstein et al. (1974) measured the kinetics and described different mechanisms involved in the hydrolysis of $\mathrm{VX}$ from pure aqueous solutions over a $\mathrm{pH}$ range from 1 to 13. Although these experiment were done only on unbuffered waters, where $\mathrm{HCl}$ and $\mathrm{NaOH}$ were used to set $\mathrm{pH}$, the equation from the resulting paper that relates the observed hydrolysis rate $\left(\mathrm{k}_{\mathrm{obs}}\right)$ to $\mathrm{pH}$ (Equation 1$)$ is often extended to applications in environmental systems (Kingery and Allen, 1995) dominated by natural buffers and other dissolved species:

$$
k_{\text {obs }}=k_{\mathrm{H}_{2} \mathrm{O}} \frac{\left[H^{+}\right]}{K_{a}+\left[H^{+}\right]}+k \frac{K_{a}}{K_{a}+\left[H^{+}\right]}+k_{\mathrm{OH}}\left[\mathrm{OH}^{-}\right] \frac{K_{a}}{K_{a}+\left[H^{+}\right]}
$$

where, $\mathrm{k}_{\mathrm{H} 2 \mathrm{O}}=2.9 \times 10^{-4} \mathrm{hr}^{-1}, \mathrm{k}=1.5 \times 10^{-2} \mathrm{hr}^{-1}, \mathrm{k}_{\mathrm{OH}}=30 \mathrm{M}^{-1} \mathrm{hr}^{-1}, \mathrm{~K}_{\mathrm{a}}=2.5 \times 10^{-9}$ (Epstein et al. 1974). The presence of other dissolved species may result in additional aqueous interactions that affect the observed VX hydrolysis rate. For example, competitive exclusion of other electron donating or withdrawing ions may slow down or accelerate VX hydrolysis, or VX affinity toward functional groups on dissolved/suspended species may cause similar changes. Thus, our hydrolysis experiments were designed as simple tests to quantitatively measure the hydrolysis rate under various aqueous conditions.

The hydrolysis rate from Epstein et al. (1974) and the hydrolysis data from this study are compared in Figure 3. Although the overall trend is similar, with slower hydrolysis at low $\mathrm{pH}$ conditions and greater hydrolysis at high $\mathrm{pH}$ conditions, it seems apparent that the type and quantity of dissolved species does significantly affect the observed hydrolysis rate. The presence of the $1 \mathrm{mM}$ buffers seem to increase the hydrolysis of VX compared to the rate in the hydrolysis equation from Epstein et al. (1974), whereas the $10 \mathrm{mM}$ carbonate buffer at $\mathrm{pH} 11$ it was slower than the equation would have predicted. If it is assumed that deionized water that has equilibrated with the atmosphere is 
affected by carbonate buffering $(\sim 0.01 \mathrm{mM})$, it appears there is only a small decline in the hydrolysis rate as $\mathrm{pH}$ decreases from $\mathrm{pH} 11$ to 5, where carbonate/bicarbonate is the dominant buffer. In addition to the overall role of buffers, it is important to note that at $\mathrm{pH} 7$ the Suwannee River fulvic acid additionally seemed to slow the hydrolysis rate of VX.

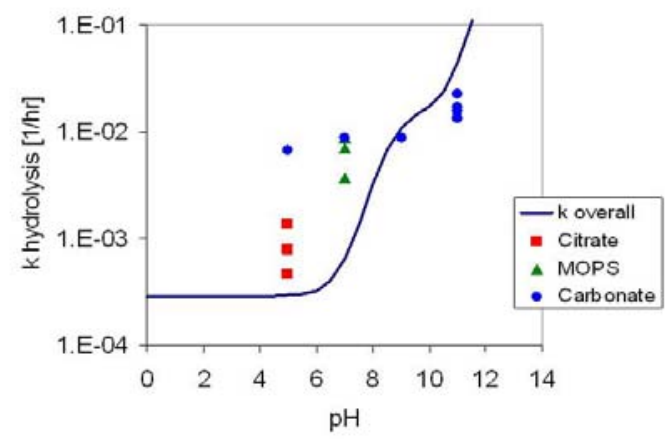

Figure 3. Comparison of experimental results from Figure $2 \mathrm{a}-2 \mathrm{~d}$ with the hydrolysis equation (1) from Epstein et al. (1974).

VX is thought to typically degrade from electron acceptance on the phosphorus due to interactions with anionic nucleophiles (Yang, 1999). Compared to the rates reported by Epstein et al. (1974), discrepancies in hydrolysis rates observed in the buffered solutions reported here reflect aqueous conditions that contain higher concentrations of nucleophiles other than hydroxide that may dominate the overall hydrolysis. The batch reactors from Epstein et al. (1974) used an autotitrator with sodium hydroxide to control $\mathrm{pH}$, whereas the batch reactor reported here controlled $\mathrm{pH}$ with various buffers. Examining relative nucleophilicities using Swain-Scott $n$ values based on reactions with methyl bromide (Schwarzenbach, et al. 1993) for some of these dissolved constituents reveals that hydroxide, $n=4.2$, has the greatest nucleophilicity of the dissolved species in these aqueous system, whereas the nucleophilicity of bicarbonate, $n=3.8$, is less than hydroxide, and acetate, $n=2.7$, is the nucleophile listed that is closest in structure to citrate. However, in our buffered solutions the equilibrium concentration of hydroxide was over two orders of magnitude less than the bicarbonate concentration over all pH ranges (Snoeyink and Jenkins, 1980). Therefore, although other dissolved species are weaker nucleophiles than hydroxide, higher concentrations of these species may result in their dominance in the hydrolysis of VX. The observed hydrolysis rates reported by Epstein et al. (1974) are likely only applicable for aqueous systems where hydroxide is the dominant nucleophile, which have limited environmental applicability, except possibly seawater. In order to predict the persistence of VX in more likely environmental aqueous matrices, a more complete understanding is required of both the potential nucleophiles that can affect hydrolysis as well as other dissolved components that may enhance or interfere with degradation.

VX Adsorption Affinity

The low volatility of VX, its different protonation states, and the hydrophobicity of the diisopropyl group suggest that VX is prone to partition onto solid surfaces. VX adsorption isotherms on materials that represent surfaces in the natural environment have never previously been reported. The VX adsorption isotherms for powdered activated charcoal (a surrogate for particulate organic matter), montmorillonite (a common clay mineral), goethite (a common iron soil mineral), and amorphous silica are shown in Figure 4. The activated charcoal clearly has the greatest affinity for VX, which should not be surprising since activated charcoal is used widely as an adsorbent for dissolved organics. This result is additionally supported by the fact that VX has a log $\mathrm{K}_{\mathrm{Ow}}$ of $\sim 2.1$ (Munro et al., 1999), and thus has a strong affinity for hydrophobic interactions. Montmorillonite has a moderate affinity for VX and the goethite has little affinity. The low affinity of VX for goethite additionally 
explains why the hydrolysis experiments that contained $1000 \mathrm{mg} / \mathrm{L}$ goethite did not have observable differences in hydrolysis rate when compared to the solutions without goethite (Figures 2a-d). The addition of fulvic acid to the solution containing montmorillonite and goethite enhanced the adsorption of VX onto goethite, but showed little effect with montmorillonite. This may be the result of fulvic acids neutralizing charge on the goethite surface, thus permitting the hydrophobic adsorption of VX. The fulvic acid did not increase or decrease VX adsorption onto montmorillonite, suggesting that VX and the fulvic acids exploit different surface sorption sites on the clay.

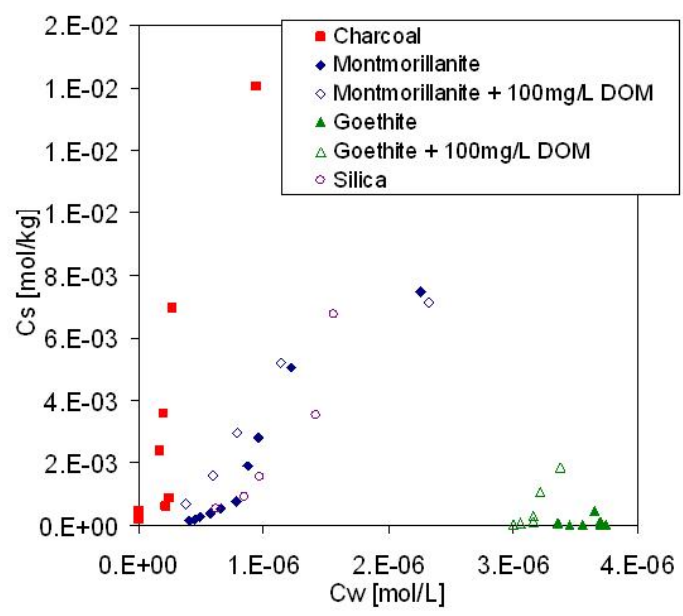

Figure 4. VX adsorption onto different substrates. Cs is the concentration on the solid substrate. $\mathrm{CW}$ is the aqueous concentration

Like VX the hydrolysis product diisopropyl-aminoethylthiol showed strong adsorption to montmoriilonite, suggesting the amino group undergoes a cation exchange mechanism in the clay structure (Fig. 5). Furthermore, it showed poor affinity to both amorphous silica and goethite. On the other hand, the ethylmethylphosphonic acid derivative demonstrated a strong adsorption to goethite but not to amorphous silica, suggesting a ligand exchange mechanism between the phosphonic acid and the iron-oxyhydroxide (McBride and Kung, 1989). If VX were to undergo simultaneous transport and hydrolysis, the conclusion from these experiments are that the VX and the diisopropyl-aminoethylthiol would preferentially accumulate in clay phases, while the phosphonic acid derivatives would accumulated in metal-oxyhydroxide phases. 


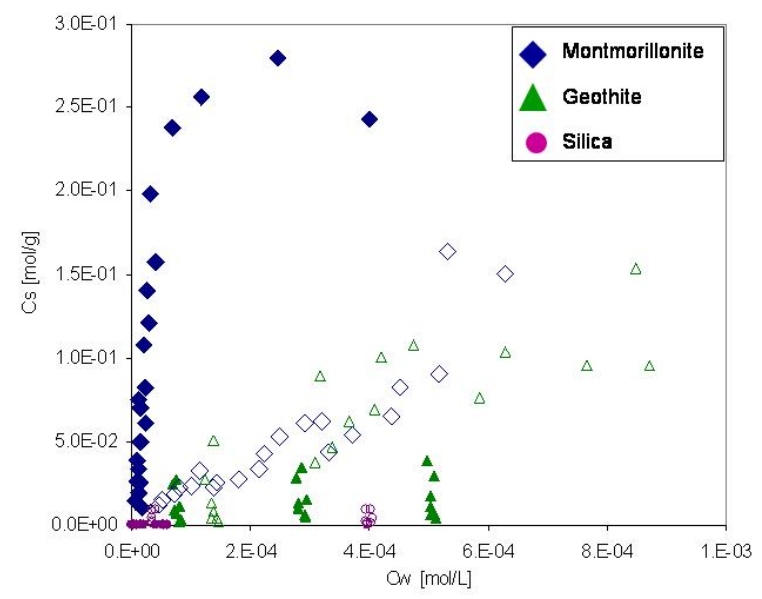

Figure 5. Adsorption isotherms of VX hydrolysis products diisopropylaminoethylthiol (solid symbols) and ethylmethylphosphonic acid (open symbols) suggest the aminothiol group is responsible for most of VX affinity for montmorillonite. Amorphous silica showed poor affinity for either product.

\section{Surface Reactions of VX with Goethite}

Studies of the persistence of VX on solid surfaces often apply it onto a dry mineral surface as a neat liquid or in a solvent and report rapid degradation of VX (Wagner et al, 2001b; Wagner et al., 1999; Groenewold et al. 1999; Verweij and Boter, 1976). Although this form of VX application is often described as adsorption, VX may not necessarily have an affinity for the mineral surface (i.e. goethite) and thus any interaction could be the result of a forced juxtaposition. In the environment, most soil mineral surfaces are coated with water and thus most interactions of VX with mineral surfaces are likely the consequence of an adsorption process where water plays a crucial role. Since the VX adsorption isotherm did not exhibit an affinity for goethite, the opportunity to examine the difference in persistence between VX application on wet and dry goethite was explored.

The results of applying VX in methylene chloride to wet and dry goethite is shown in Figure 6. The control (empty vial) and the dry sand show 100\% recovery of the VX applied in the solvent and extracted the next day with water, thus ruling out vapor loss using this approach. The VX applied to the dry goethite had $0 \%$ recovered, and $>90 \%$ of the degradation product EMPA was extracted. VX applied to the wet goethite had $\sim 60 \%$ recovered, with $\sim 30 \%$ of the degradation product EMPA extracted. Lastly, VX applied to wet goethite, where the methylene chloride and the water were allowed to dry completely also had $0 \% \mathrm{VX}$ recovered, and $\sim 100 \%$ of the EMPA was extracted.

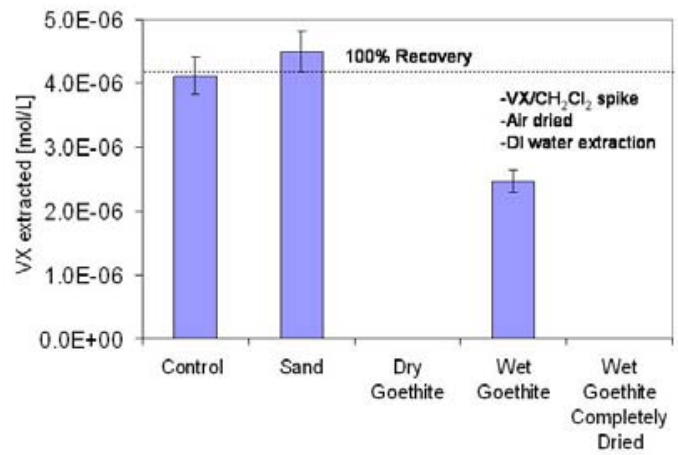

Figure 6. Degradation results from applying VX onto wet and dry goethite. 
This difference in persistence is the result of specific adsorption (loss of waters of hydration) on dry goethite (Wijnja and Schulthess, 2000) that allows electron interactions between adsorbent and adsorbate that facilitate the catalytic degradation of VX, whereas wet goethite had no affinity for VX in the aqueous phase and the waters of hydration act as a barrier to electron interactions. Dannenburg and Pehkonen (1998) demonstrated that goethite was able to catalytically hydrolyze organophosphorus pesticides when adsorbed to specific binding sites. It is hypothesized that specific adsorption onto goethite reduces the electron density at the central phosphorus and enhances nucleophilic attack. Thus, the likely cause of only $\sim 60 \% \mathrm{VX}$ recovery from wet goethite was due to some drying of the mineral surface overnight, permitting catalytic degradation, while most of the remaining mineral surface remained hydrated and prevented specific adsorption of VX. The dramatic differences in persistence when applying VX to wet and dry minerals reinforces the need to conduct experiments under realistic environmental conditions if the results are to be used for predicting the fate of VX in the environment.

\section{CONCLUSIONS}

Understanding the ultimate fate of VX in environmental systems involves a complex interaction of factors related to the solid, liquid, and gaseous phases. These results indicate that the hydrolysis equation by Epstein et al. (1974) may be inadequate to accurately predict the aqueous hydrolysis rate in environmental systems where natural dissolved species are present, and highlights the need to examine in more detail the role of naturally occurring nucleophiles in VX hydrolysis. The adsorption isotherms demonstrate the natural affinities VX has to a few naturally occurring minerals, but further study of additional substrates and various aqueous conditions is needed to understand how the affinities change in different soil and aqueous compositions. The persistence of VX on goethite is strongly affected by the presence or absence of water, which may also be true for other minerals that catalyze VX degradation. Still, there is much information that needs to be acquired if we intend to have a dependable predictive capability of the environmental fate of VX. An understanding of the dominant mechanisms that control the physio-chemical fate and persistence of VX in complex environments can only be determined by initially performing quantitative experiments examining individual factors in simple systems, such as in this study, and then progressively increasing the matrix complexity such that various mechanisms can be integrated into reliable model of natural systems.

\section{ACKNOWLEDGEMENTS}

This work was performed under the auspices of the U. S. Department of Energy (DOE) by the University of California, Lawrence Livermore National Laboratory (LLNL) under Contract No. W7405-Eng-48. The project (03-ERD-022) was funded by the Laboratory Directed Research and Development Program at LLNL. 


\section{REFERENCES}

Aubin, A.J. and A.E. Smith, 1992, Extraction of $\left[{ }^{14} \mathrm{C}\right]$ glyphosate from Saskatchewan soils. J. Agric. Food Chem., 40, 1163-1165.

Baldwin, D.S., J.K. Beattie, L.M. Coleman, D.R. Jones, 2001, Hydrolysis of an organophosphate ester by manganese dioxide. Environ. Sci. Technol., 35, 713-716.

Black, R.M. and Read, R.W., 1997, Application of liquid chromatography-atmospheric pressure chemical ionization mass spectrometry, and tandem mass spectrometry, to the analysis and identification of degradation products of chemical warfare agents. Jour. Chrom. A, 759, 79-92.

Cahill, T.M. and D. MacKay, 2003, A high-resolution model for estimating the environmental fate of multi-species chemicals: application to malathion and pentachlorophenol. Chemosphere, 53, 571581.

Chang, J.C., P. Franzese, K. Chayantrakom, S.R. Hanna, 2003, Evaluations of CALPUFF, HPAC, and VLSTRACK with two mesoscale field datasets. J. Appl. Meteor., 42, 453-466.

Clark, V.M., D.W. Hutchinson, A.I. Kirby, S.G. Warren, 1964, Phosphorylierungsmittel-bauprinzip und reacktionweise. Angew. Chem., 76, 704-712.

Clark, D.N., 1989, Review of Reactions of Chemical Agents in Water. Final Report (Task 80) to US Army Medical Research and Development Command. Army Project Order No. 88PP8847. Battelle, Columbus, OH, 72 pp.

Cousins, I.T. and D. MacKay, 2001, Gas-particle partitioning of organic compounds and its interpretation using relative solubilities. Environ. Sci. Technol., 35, 643-647.

Croddy, E., 2002, Chemical and Biological Warfare. Springer-Verlag: New York, 306 pp.

Dannenberg, A.; Pehkonen, S.O. Investigation of the heterogeneously catalyzed hydrolysis of organophosphorus pesticides. Journal of Agricultural and Food Chemistry. 1998. 46:325-334.

Epstein, J., Demek, M., Harrison, B.L., Kolmerten, J., 1958, Project Little Seven Studies. II. Studies on VX Behavior in Soil. US Army Chemical Corps Research and Development Command, Edgewood Aresenal, MD.

Epstein, J., 1970, Rate of decomposition of GB in seawater. Science, 170, 1396-1398.

Epstein, J.; Callahan, J.J.; Bauer, V.E. (1974) The kinetics and mechanisms of hydrolysis of phosphonothiolates in dilute aqueous solutions. Phosphorus. Vol. 4:157-163

Fest, C. and K.-J. Schmidt, 1982, The Chemistry of Organophosphorus Pesticides. Springer-Verlag: Berlin, $360 \mathrm{pp}$.

Fest, C. and K.-J. Schmidt, 1983, Organophosphorus insecticides. In Buchel, K.H. (ed) Chemistry of Pesticides. John Wiley \& Sons: New York, pp. 48-125.

Groenewold, G.S., Appelhans, A.D., Gresham, G.L., Olson, J.E., Jeffery, M., Wright, J.B., 1999, Analysis of VX on soil particles using ion trap secondary ion mass spectrometry. Anal. Chem., 71, 2318-2323.

Harris, R. and J. Paxman, 1982, A Higher Form of Killing. Hill and Wang: New York, 274 pp.

Hopkins, E.H., D.J.Hippe, E.A. Frick, G.R. Buell, 2000, Organophosphorus pesticide occurrence and distribution in surface and ground water of the United States, 1992-97, US Geological Survey Open File Report 2000-187, 4 pp.

Kaajik, J. and Friflink, C., 1977, Degradation of S-2-Di-Isopropylaminoethyl O-Ethyl methylphosphonothioate in soil. Sulfur containing products. Pestic. Sci., 8, 510-514.

King, J.M., 2000, Chemical and biological defense information analysis center (CBIAC). Viewgraph presentation to the CBTAP Agent Fate Workshop, November 28-29, 2000.

Kingery, A.F.; Allen, H.E., 1995, The environmental fate of organophosphorus nerve agents: A review. Toxicol. Environ. Chem., 47:155-184. 
Korenyi-Both, A.L., L. Sved, G.E. Korenyi-Both, D.J. Juncer, A. Szekely, 2000, The role of the sand in chemical warfare agent exposure among Persian Gulf war veterans: al eskan disease and "dirty dust". Military Med., 165, 321-336.

Larsson, L., 1953, The hydrolysis of dimethylamido-ethoxy-phosphoryl cyanide (tabun). Acta Chem. Scan., 7, 306-314.

MacKay, D and S. Paterson, 1981, Calculating fugacity. Environ. Sci. Technol., 15, 1006-1014.

MacKay, D., S. Paterson, B. Cheung, W.B. Neely, 1985, Evaluating the environmental behavior of chemicals with a level III fugacity model. Chemosphere, 14, 335-374.

MacKay, D and S. Paterson, 1991, Evaluating the multimedia fate of organic chemicals: A level III fugacity model. Environ. Sci. Technol., 25, 427-436.

Maddalena, R.L., T.E. McKone, D.W. Layton, D.P.H. Hsieh, 1995, Comparison of multi-media transport and transformation models: regional fugacity model vs. CalTOX. Chemosphere, 30, 869889.

McConnell, J.S. and L.R. Hossner, 1985, pH-dependent adsorption isotherms of glyphosate. J. Agric. Food Chem., 33, 1075-1078.

McBride, M. and Kung, K., 1989, Complexation of glyphosate and related ligands with iron (III). Soil Sci. Soc. Am. J., 53, 1668-1673.

Meikle, R.W. and C.R. Youngson, 1978, The hydrolysis rate of chlorpyrifos, O-O-diethyl O-(3,5,6trichloro-2-pyridyl) phosphorothioate, and its dimethyl analog, chlorpyrifos-methyl, in dilute aqueous solution. Arch. Environ. Contam. Toxicol., 7, 13-22.

Munro, N.B.; Talmage, S.S.; Griffin, G.D.; Waters, L.C.; Watson, A.P.; King, J.F.; Hauschild, V. (1999) The source, fate, and toxicity of chemical warfare agent degredation products. Environmental Health Perspectives. Vol. 107(12):933-974

National Research Council (NRC), 1997, Subcommittee on toxicity values for selected nerve agents and vesicant agents. Review of acute human-toxicty estimates for selected chemical warfare agents. National Academy Press: Washington, D.C.

Pearson, R.G., 1963, Hard and soft acids and bases. J Am. Chem. Soc., 85, 3533-3539.

Piccolo, A. and Celano, G., 1994, Hydrogen-bonding interactions between the herbicide glyphosate and water-soluble humic substances. Environ. Toxicol. Chem., 13, 1737-1741.

Piccolo, A., G. Celano, P. Conte, 1996, Adsorption of glyphosate by humic substances. J. Agric. Food Chem., 44, 2442-2446.

Quin, L.D., 2000, A Guide to Organophosphorus Chemistry. John Wiley \& Sons: New York, 394 pp.

Read, R.W.; Black, R.M. Rapid screening procedures for the hydrolysis products of chemical warfare agents using positive and negative ion liquid chromatography -mass spectrometry with atmospheric pressure chemical ionization. Journal of Chromatography A. 1999. 862:169-177.

Schwarzenbach, R.P.; Gschwend, P.M.; Imboden, D.M. Environmental Organic Chemistry. John Wiley \& Sons, Inc. New York. 1993. p. 359.

Schwertmann, W.; Cornell, R.M. Iron Oxides in the Laboratory: Preparation and Characterization. VCH, Weinheim. 1991. pp 64-71.

Smart, J.K., 1997, History of chemical and biological warfare: an American perspective. In Sidell, F.R., E.T. Takafuji, D.R. Franz (eds) Medical Aspects of Chemical and Biological Warfare. Office of Surgeon General at TMM Publications, Borden Institute: Washington, DC. 696 pp. last accessed 01/25/05 at http://www.nbc-med.org/SiteContent/HomePage/WhatsNew/MedAspects/Ch2electrv699.pdf

Snoeyink, V.L.; Jenkins, D. Water Chemistry. John Wiley \& Sons, Inc. New York. 1980. p. 162-164. Verweij, A. and Boter, H.L., 1976, Degradation of S-2-Di-Isopropylaminoethyl O-Ethyl Methylphosphonothioate in soil. Phosphorus-containing products. Pestic. Sci., 7, 355-362.

Wagner, G.W., Bartram, P.W., Koper, O., Klabunde, K.J., 1999, Reactions of VX, GD, and HD with nanosize MgO. Jour. Phys. Chem. B, 103, 3225-3228. 
Wagner, G.W., O’Connor, R.J., Procell, L.R., 2001a, Preliminary study on the fate of VX in concrete. Langmuir, 17, 4336-4341.

Wagner G.W.; Procell, L.R.; O’Connor, R.J.; Munavalli, S.; Carnes, C.L.; Kapoor, P.N.; Klabunde, K.J., 2001b, Reactions of VX, GB, GD, and HD with nanosize $\mathrm{Al}_{2} \mathrm{O}_{3}$ : Formation of aluminophosphonates. J. Am. Chem. Soc., 123, 1636-1644.

Warner, S, J.F. Heagy, N. Platt, D. Larson, G. Sugiyama, J.S. Nasstrom, K.T. Foster, S. Bradley, G. Bierberbach, 2001, Evaluation of transport and dispersion models: a controlled comparison of HPAC and NARAC predictions. $5^{\text {th }}$ Annual George Mason University Transport and Dispersion Modeling Workshop, Fairfax, VA, July 18-19, 2001, 280 pp.

Warner, S, N. Platt, J.F. Heagy, 2004, Comparisons of transport and dispersion model predictions of the URBAN 2000 field experiment. J. Appl. Meteor., 43, 829-846.

Wiener, S.W. and R.S. Hoffman, 2004, Nerve agents: a comprehensive review. J. Intensive Care Med., $19,22-37$

Wijnja, H.; Schulthess, C.P., 2000, Vibrational spectroscopy study of selenate and surface adsorption mechanism on Fe and Al (Hydr)oxide surfaces. J. Colloid Interface Sci, 229, 286-297.

Wolfe, N.L., R.G. Zepp, J.A. Gordon, G.L. Baughman, D.M. Cline, 1977, Kinetics of chemical degradation of malathion in water. Environ. Sci. Technol., 11, 88-93.

Yang, Y-C, 1995, Chemical reactions for neutralising chemical warfare agents. Chem. Ind., 8, 334337.

Yang, Y. Chemical detoxification of nerve agent VX. Accounts of Chemical Research. 1999. 32(2):109-115. 